\title{
USING POLAR NSO COMPOUNDS TO IMPROVE OUR UNDERSTANDING OF RESERVOIR GEOCHEMISTRY - A CASE STUDY FROM VALHALL, NORWAY
}

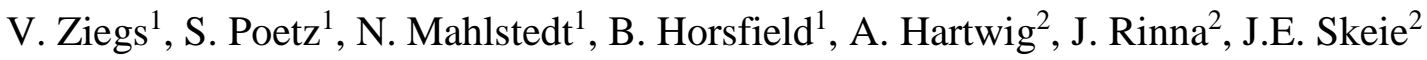 \\ ${ }^{1}$ German Research Centre for Geosciences GFZ Potsdam, Germany, ${ }^{2}$ Aker BP ASA, Norway
}

\section{Introduction}

While the hydrocarbon fraction of a petroleum fluid hosts valuable information on mainly source and maturity, the more polar NSO compounds are potential tracers for reservoir processes like filling history and fractionation due to production. Due to their polar nature, they interact more strongly with other polar phases in a petroleum system such as the residual kerogen, formation water, and clay minerals.

The giant Valhall oil field, an elongated anticline structure which is located in the SW of the Norwegian sector of the North Sea, is a well suited candidate to investigate those interactions. Main reservoir strata are Upper Cretaceous chalks of the Tor and Hod Formations with porosities in the range of 30 to $50 \%$ that increase from the flanks towards the crest. The early mature black oils sourced from $<1000 \mathrm{~m}$ thick Upper Jurassic marine shales with varying terrigenous organic matter (OM) contribution (Hughes et al., 1985; Cornford, 1994) migrated through thick packages of OM-poor shales.

In this communication, we address the chemical heterogeneities of the in-reservoir retained petroleum and the produced fluids to identify migration routes. More importantly, we give implications on production fractionation, using the compositions of NSO compounds with different polarities from ultra-high resolution FT-ICR-MS combined with various ionization techniques. Therefore, we sampled 9 pairs of oils and corresponding reservoir core bitumens from identical wells or nearby subsurface positions in the same reservoir compartments at the crest and the flanks of the Valhall field as well as from an oil retrieved from the shallow overburden above the Valhall crest.

\section{Results \& Discussion}

The gross chemical composition of medium polarity aromatic NSO compounds accessible by atmospheric pressure photoionization (APPI) in produced oils and reservoir bitumen samples from the reservoir crest is quite similar. Aromatic hydrocarbons (HC) as well as compounds with 1 nitrogen atom $\left(\mathrm{N}_{1}\right)$ and 1 oxygen atom $\left(\mathrm{O}_{1}\right)$ are the major compound classes, accompanied by minor contributions from $\mathrm{S}_{1}, \mathrm{~S}_{1} \mathrm{O}_{1}$ and $\mathrm{N}_{1} \mathrm{O}_{1}$ compounds. Molecules with higher number of heteroatoms (e.g. $\mathrm{O}_{2-4}$ species) are preferentially retained in the reservoir rocks (see pie charts, Fig. 1). Venn analysis revealed that mainly less polar compounds from $\mathrm{HC}, \mathrm{S}_{1}$ and $\mathrm{N}_{1}$ compound classes are unique in produced oils. Moreover, produced oils show relatively higher contributions of least aromatic and highest aromatic compounds (lowest and highest DBE classes in a compound class), here shown for $\mathrm{O}_{1}$ compounds that occur in both sample types, oils and core extracts. Only the lower DBE classes of the $\mathrm{O}_{1}$ compounds show variations in their carbon number distributions. While oils are relatively enriched in higher carbon numbers $\left(\mathrm{C}_{29+}\right)$, core extracts contain slightly more $\mathrm{C}_{29}$ carbon numbers influencing the physical properties of the individual molecule. 


\section{Conclusion}

Petroleum NSO compounds have a major impact on fluid flow in conventional and unconventional petroleum reservoirs (Bennett and Larter, 2000; Jarvie, 2014). Using ultrahigh resolution mass spectrometry, we show differences in the polarity, aromaticity and molecular size of NSO compounds in retained reservoir bitumen and produced oil which seems to be a result of oil-water or oil-rock interactions. For a broader interpretation of the individual significance of polarity, aromaticity and aliphaticity on fractionation processes, all Valhall samples will be analysed with the described method.

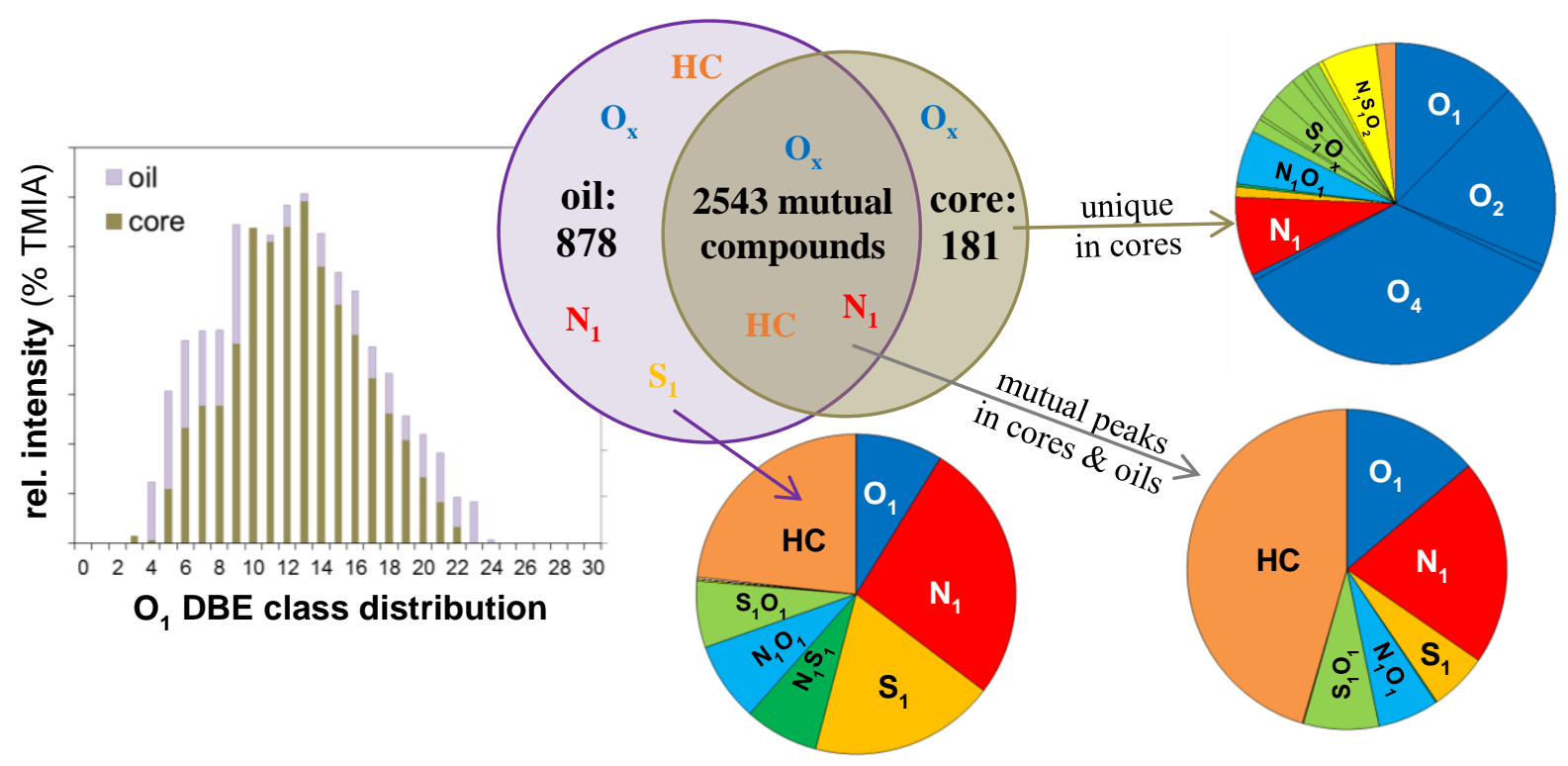

Figure 1 Compositional production-related fractionation in APPI (+) FT-ICR-MS data between a produced oil and the corresponding reservoir core extract at the Valhall crest. The Venn diagram illustrates quantitative variations between the producible and in-reservoir retained phases, while the pie charts show the respective elemental class distributions of signals unique to or mutual in oils and cores. DBE class distributions of the $O_{1}$ class compare aromaticity and molecular size of produced and retained petroleum.

\section{References}

Bennett, B., Larter, S., 2000. Significance of non-producible petroleum compounds in reservoirs: Influence on petrophysical/core parameters. DiaLog 8.

Cornford, C., 1994. Mandal-Ekofisk(!) petroleum system in the Central Graben of the North Sea, in: Magoon, L.B., Dow, W.G. (Eds.), The petroleum system - from source to trap. AAPG Tulsa, Oklahoma, pp. 537-571.

Hughes, W.B., Holba, A.G., Miller, D.E., Richardson, J.S., 1985. Geochemistry of the greater Ekofisk crude oils, in: Thomas, B.M., Doré, A.G., Eggen, S., Home, P.C., Larsen, R.M. (Eds.), Petroleum geochemistry in exploration of the Norwegian Shelf. Graham \& Trotman, for Norwegian Petroleum Society, London, pp. 75-92.

Jarvie, D.M., 2014. Components and processes affecting producibility and commerciality of shale resource systems. Geologica acta 12, 307-325. 